\title{
Retrofitting of vapour compression refrigeration trainer by an eco-friendly refrigerant
}

\author{
Alka Bani Agrawal and Vipin Shrivastava \\ Department of Mechanical Engineering, University Institute of Technology, RGPV, Bhopal-462024, India \\ alk_agr@yahoo.co.in; vipin_shrivastava07@rediffmail.com
}

\begin{abstract}
After years of successful deliberations for tackling the grievous problem of ozone depletion, the United Nation's environmental protection agency concluded multinational agreement called "Montreal Protocol' for controlling the use of gases threatening the ozone layer. The successful implementation of the "Montreal Protocol' in developed countries is being appreciated for its significant reduction in emission level of ozone depleting substances Now it is the turn of developing countries to fulfill their obligation of Montreal Protocol. The dead line for complying with the phase out of chloroflurocarbon in developing countries like India is 2010. The refrigeration industry has accepted the challenge of chloroflurocarbons phase out and new eco-friendly refrigerant like hydroflurocarbons and hydrocarbons are replacing chloroflurocarbons in all commercial and industrial application. Vapour compression refrigeration trainer is an important equipment of thermal engineering lab of mechanical engineering department which operated using chlorofluorocarbon 12. CFC12 is the most important member of CFC refrigerants which are being targeted for phase out in India by 2010. In this paper, performance valuation of many eco-friendly hydrocarbon refrigerants for replacing CFC12 in the trainer has been done and a suitable drop in alternative refrigerant for retrofitting has been identified.
\end{abstract}

Keywords: Ozone depletion; montreal protocol; eco-friendly refrigerant; hydrocarbon refrigerant; retrofitting.

\section{Introduction}

Most of the refrigeration and air-conditioning system operate on vapour compression refrigeration cycle in which the refrigerant change phases from liquid to gas and then gas to liquid in a closed cycle to generate cooling in the evaporator. Refrigerants used in these systems are predominantly from a group of compounds called halocarbons (halogenated hydrocarbons) or specifically chlorofluorocarbons (CFC). In 1974, Sherwood Rowland and Mario Molina predicted that chlorofluorocarbon refrigerant gases would reach the high stratosphere and there damage the protective mantle of the oxygen allotrope, ozone. In 1985, with discovery of the "ozone hole" over the Antarctic, the prediction of Rowland and Molina's was proved correct. CFCs are nontoxic, non-flammable and are used extensively as refrigerants in refrigeration units, aerosol propellants, electronic cleaning solvents, and blowing agents. Over time, these CFCs get released into the air and often, strong winds carry them into the stratosphere. When CFC molecules drift into the stratosphere, the UV-B and UV-C radiation from the sun releases their chlorine atoms. Complex chemical reactions in the atmosphere result in the formation of chlorine monoxide, which reacts with the ozone molecule to form oxygen and regenerates more chlorine atoms that carry on converting the ozone molecules. Each chlorine atom can destroy as many as 100,000 ozone molecules over 100 years. Thus, even a small amount of CFCs can cause tremendous damage to the ozone layer.

\section{Montreal protocol}

In 1987, several countries across the world signed an international treaty, the Montreal protocol, to control substances that deplete the ozone layer. According to this protocol, countries would phase out CFCs and other ODS as per a given schedule, with a complete halt by 2010 . 190 countries are signatories to the Montreal protocol. Under this agreement, the use of CFCs as refrigerants in all commercial and industrial refrigeration and airconditioning equipments has been banned in 1999 in all developed countries. Countries like India which have ODS consumption below the threshold annual value of $0.3 \mathrm{~kg}$ per capita are required to freeze the consumption of CFC by 1999 , then reduce the use by $50 \%$ by 2005 and complete phase out by 2010 (Agrawal, 2001). It is believed that if the international agreement is adhered to the ozone layer is expected to recover by 2050 . Due to its widespread adoption and implementation it has been hailed as an example of exceptional international cooperation with Kofi Annan, the General Secretary,UN, quoted as saying that "perhaps the single most
Research article

CIndian Society for Education and Environment (iSee) J.Sci.Technol.
"Eco-friendly refrigerant"

http://www.indjst.org
Alka \& Vipin Indian 
successful international agreement to date has been the Montreal protocol.

India's commitment to the montreal protocol

India became party to the Montreal protocol on Sept 17 , 1992. India mainly produced and used seven of the 20 substances controlled under the Montreal protocol. These are CFC-11, CFC12, CFC113, Halon1211, Halon1301, CTC, methyl chloroform and methyl bromide. India had prepared a detailed country programme (CP) in 1993 to phase out ODS in accordance with its national industrial development strategy (INFRAS, 2000). The objectives of the CP were to phase out ODS without undue economic burden to both consumers and industry manufacturing equipments using ODSs and provided India with an opportunity to access the protocol's financial mechanism. The other objectives of the CP also include minimization of economic dislocation as a result of conversion to non-ODS technology, maximization of indigenous production, preference to one time replacement, emphasis is on decentralized management and minimization of obsolescence. In 1991, the total ODS consumption in the refrigeration and air-conditioning sector in India was 1,990 MT. This constituted about 39\% of India's total consumption of CFCs. About two-thirds of this consumption was estimated to be used in servicing of existing equipment. The growth rate in this sector was forecast at $10-20 \%$ annually until 2010 . The refrigeration and air-conditioning sector was therefore identified as a priority sector in India for initiating phase-out activities (Kapil, 2008).

In India, the manufacturing of new products using R12 has been banned on Dec 31, 2002. As of Jan 1, 2007, the country achieved an $85 \%$ reduction in CFC production and consumption-a full year ahead of the montreal protocol schedule for CFC phase out for article 5 countries. Now, it must focus on further reducing its consumption to zero by 2010 . In anticipation of this step down in just few months, CFC manufacturer have already stopped supplying CFCs for consumption in India. This action will result in shortages for servicing CFC equipment in the very near future.

\section{Retrofitting \\ Imminent CFC shortages would threaten the useful life of the appliance of CFC equipment.} As the CFC shortages increase, the cost of CFCs will rise, along with the operating costs of the equipment. "Retrofitting" is the only long term and the most effective solution for discontinuing and reducing the CFC emissions from existing appliances. Retrofitting is the process by which the equipment currently using an ODS refrigerant is made to operate on a non ODS refrigerant, without major effects on the performance of the equipment and without significant modifications or changes for the equipment, ensuring that existing equipment operates until the end of it's economic life. It has been proved by various case studied that retrofitting is economically viable in small scale refrigeration equipment (Othmar \& Adrian, 1998) than in large capacity systems.

\section{Objective}

The vapour compression refrigeration trainer is an important refrigeration unit of the thermal lab of the department of mechanical engineering of University institute of technology, the constituent college of the Rajiv Gandhi technical university, which controls engineering education in the state of Madhya Pradesh. The vapour compression refrigeration trainer operates on refrigerant $\mathrm{R} 12$ which is most important CFC refrigerant identified for phase out in the country as per its commitment in the Montreal protocol. The trainer is frequently used for experimentation by graduate and post graduate students of the department. The institute has been one of the few institutes selected for funding for research work under World Bank project TEQIP. A research work was undertaken for finding the most suitable eco-friendly refrigerant for replacing ozone depleting refrigerant $\mathrm{R} 12$. In the paper, the performance evaluation of alternative eco-friendly refrigerants in the vapour compression refrigeration trainer has been done. Then most suitable refrigerant has been selected for replacing harmful refrigerant.

\section{Technical detail of refrigeration trainer}

The 'UNICOOL' make vapour compression refrigeration trainer provides basis understanding of domestic refrigerator (Neelam engg.Agra). A small heater provided in evaporator simulates heat load. Various measurements like evaporating and condensing pressure and temperature, input to compressor and heater enable the students to calculate power consumption and theoretical and actual COP of the refrigeration trainer. It consists of controls and components: 1) Hermitically sealed KIRLOSKAR compressor, having capacity $1 / 3$ tons using R12 operating between 0 and $55^{\circ} \mathrm{C}$ with genuine electrical accessories, 2) Insulated evaporator with variable input heater inside, 3) Natural convection air cooled condenser, 4) Capillary tube as expansion device and 5) Measuring gauges for temperature and pressure at all control points.

\section{Eco-friendly refrigerant}

Hydrocarbon refrigerants are environmentally friendly, non-toxic, non-ozone depleting replacement for chlorofluorocarbons (CFCs), hydrochlorofluorocarbons (HCFCs) and hydrofluorocarbons (HFCs) (Arora, 2000). From a chemical point of view, a hydrocarbon is the simplest organic compound, consisting entirely of hydrogen and carbon. Hydrocarbons $(\mathrm{HC})$ are naturally occurring substances. The majority can be found in crude oil, where decomposed organic matter provides an
Research article

CIndian Society for Education and Environment (iSee) J.Sci.Technol.
"Eco-friendly refrigerant"

http://www.indjst.org
Alka \& Vipin Indian 
abundance of carbon and hydrogen. The hydrocarbons that can be used as a refrigerant in cooling \& heating applications are: R170 - Ethane - $\mathrm{C}_{2} \mathrm{H}_{6}, \mathrm{R} 290$ - Propane $\mathrm{C}_{3} \mathrm{H}_{8}$, R600- N-Butane- $\mathrm{C}_{4} \mathrm{H}_{10}, \mathrm{R} 600$ a- Isobutane (2Methylpropane) - $\mathrm{C}_{4} \mathrm{H}_{10}, \mathrm{R} 1270$ - Propylene (Propene) $\mathrm{C}_{3} \mathrm{H}_{6}$ and R1150 - Ethylene $-\mathrm{C}_{2} \mathrm{H}_{4}$.

However, the most commonly used $\mathrm{HC}$ refrigerants are propane (mainly in commercial \& industrial freezers, air conditioning \& heat pumps) and isobutane (in domestic refrigerators \& freezers). hydrocarbon refrigerants has been done by using the simulation process. The highly rated vapour compression refrigeration design program CYCLE-D of NIST (National Institute of Standard and Technology), Gaithersburg, USA was used for simulation. The CYCLE-D simulation program is a very versatile tool being used for finding alternative eco-friendly refrigerant for replacing environmentally harmful refrigerants in all types of refrigeration application. The performance results of simulation, in terms of mass flow of refrigerant, power consumption, volumetric refrigeration capacity, refrigerating effect, discharge temperature at compressor outlet and coefficient of performance of the vapour compression refrigeration trainer when alternative hydrocarbon refrigerants are used in place of $\mathrm{R} 12$ are presented in Table 1.

\section{Discussion}

From the study of performance results of the eco-friendly hydrocarbon refrigerants when they are used as a
place of R12 in the vapour compression

Environment friendly properties of hydrocarbons

Non-ozone depleting: Ozone depletion potential $=0$.

Non climate damaging: Global warming potential = for most $\mathrm{HCs}$ below 3 .

\section{Non-toxic}

Safe: with proper handling

Energy-efficient: usually better energy efficiency than CFC or HFC systems.

Easy replacement: able to replace many CFC gases in existing systems without the need to change components or oils.

Cost-efficient: low refrigerant purchase price as well as lower system running cost.

\section{Performance evaluation of eco-friendly refrigerant}

The performance evaluation of the eco-friendly

Table 2. Performance results of eco-friendly hydrocarbon mixture refrigerants

\begin{tabular}{|l|c|c|c|c|c|c|}
\hline $\begin{array}{l}\text { Refrigerant } \\
\text { (Ratio) }\end{array}$ & $\begin{array}{c}\text { Mass } \\
\text { flow in } \\
\text { L/sec }\end{array}$ & $\begin{array}{c}\text { Power } \\
\text { consum } \\
\text { ption in } \\
\text { kW }\end{array}$ & $\begin{array}{c}\text { Discharge } \\
\text { temp. at } \\
\text { compressor } \\
\text { outlet in }{ }^{\circ} \mathrm{C}\end{array}$ & $\begin{array}{c}\text { Volumetric } \\
\text { refrigeration } \\
\text { capacity in } \\
\mathrm{KJ} / \mathrm{m} 3\end{array}$ & $\begin{array}{c}\text { Press } \\
\text {-ure } \\
\text { ratio }\end{array}$ & C.O.P. \\
\hline R12 & 0.687 & 0.41 & 71.1 & 1532.1 & 4.42 & 2.89 \\
\hline $\begin{array}{l}\text { R290/R600a } \\
(0.25 / 0.75)\end{array}$ & 0.979 & 0.41 & 62.5 & 1075.6 & 4.85 & 2.85 \\
\hline $\begin{array}{l}\text { R290/R600a } \\
(0.5 / 0.5)\end{array}$ & 0.775 & 0.41 & 66.5 & 1359.1 & 4.61 & 2.82 \\
\hline $\begin{array}{l}\text { R290/R600a } \\
(0.75 / 0.25)\end{array}$ & 0.632 & .42 & 68.1 & 1666.5 & 4.34 & 2.76 \\
\hline $\begin{array}{l}\text { R290/R600a } \\
(0.7 / 0.3)\end{array}$ & 0.657 & 0.42 & 67.9 & 1602.9 & 4.40 & 2.77 \\
\hline $\begin{array}{l}\text { R290/R600a } \\
(0.64 / 0.36)\end{array}$ & 0.689 & 0.42 & 67.5 & 1528.1 & 4.46 & 2.79 \\
\hline
\end{tabular}

Research article

CIndian Society for Education and Environment (iSee) J.Sci.Technol. refrigerant in place of $\mathrm{R} 12$ in the vapour compression
refrigeration trainer for the same cooling, it is clear that only R600 performs better with higher COP value. R1150 has the lowest discharge temperature as compared to all other refrigerants but it gives the lowest COP value of 2.10 also. R1270 requires the lowest mass flow of refrigerant for giving the same cooling effect. Volumetric refrigeration capacity, which indicates the compressor displacement required, is higher for R290,R1270 and smaller for R600, R600a and R1150 which means that all these refrigerants will require either a larger or smaller compressor for producing the same cooling effect in the refrigeration trainer. A drop in replacement refrigerant should have a similar volumetric refrigeration capacity to R12 so that it could be used without change of compressor which is the most important component of a refrigeration unit. To fulfill this requirement, a mixture refrigerant with one component having a higher volumetric refrigeration capacity and one with lower volumetric refrigeration capacity is desired. Hydrocarbon mixtures of R290 (higher volumetric refrigeration capacity) and $\mathrm{R} 600 \mathrm{a}$ (lower volumetric refrigeration capacity) are available in the markets. Performance of binary mixtures of different composition of R290 and $\mathrm{R} 600 \mathrm{a}$ are studied to select most suitable mixture for selecting a drop in replacement for R12 and results are tabulated in Table 2.

From the study of performance parameters of binary mixtures of propane (R290) and Isobutane 
Table 3. Environmental properties of hydrocarbon mixture refrigerants

\begin{tabular}{|l|c|c|c|c|}
\hline \multicolumn{1}{|c|}{ Refrigerant } & Natural product & $\begin{array}{c}\text { Atmospheric } \\
\text { lifetime (yrs) }\end{array}$ & $\begin{array}{c}\text { Global warming potential } \\
\text { (GWP) }\end{array}$ & $\begin{array}{c}\text { Ozone depletion } \\
\text { potential (ODP) }\end{array}$ \\
\hline CARE 10(R600a) & Yes & $<1$ & $<3$ & 0 \\
\hline $\begin{array}{l}\text { CARE 30(blend of HC-600a } \\
\text { (isobutane) and HC-290 (propane) }\end{array}$ & Yes & $<1$ & $<3$ & 0 \\
\hline CFC-12 & No & 130 & 8500 & 0.9 \\
\hline HFC-134a & No & 15 & 1300 & 0 \\
\hline CARE 40 R-290 (propane) & Yes & $<1$ & $<3$ & 0 \\
\hline
\end{tabular}

(R600a), it is clear that as the percentage of propane increases, the volumetric refrigeration capacity of mixture refrigerants also increases accompanied by small reduction of the COP of the refrigeration trainer. The discharge temperature at compressor outlet is lower as compared to R12 for all mixtures. The mass flow of refrigerant decreases substantially as the proportion of isobutene increases in the mixture. The binary mixture in the ratio of $64 \%$ and $36 \%$ of $\mathrm{R} 290$ and R600a respectively has matching volumetric refrigeration capacity to R12; therefore this mixture is a retrofit or drop in substitute of R12 for use in the vapour compression refrigeration trainer. The mixture has a similar mass flow rate and pressure ratio in the system. It will give a cooler running because of low value of discharge temperature as compared to R12. The requirement of compressor power is more resulting in smaller COP of the system.

\section{Conclusion}

The selected hydrocarbon mixture of propane and isobutane is the drop in refrigerant for replacing R12 in the vapour compression refrigeration trainer of the thermal engineering lab. The mixture of R290 and R600a is available in the market as CARE range of hydrocarbon refrigerants can be used for retrofitting of refrigeration trainer as per the standard guidelines. This mixture is also compatible with mineral oil being used in the trainer. As the total charge amount of mixture is small, the safety of system could be ensured by strictly adhering to the standards applicable for handling such refrigerants. This will achieve the objective of the research as the selected refrigerant is a natural product with very favorable environmental properties (Table 3) (CARE, 2009). By retrofitting the trainer, the unit can be used continuously and will help in achieving the country's target of phasing out of all CFC refrigerants by 2010 as stipulated in Montreal protocol.

\section{References}

1. Agrawal RS (2001) Montreal protocol on refrigeration and air conditioning industry. Proc. of Int. conf. on emerging technologies in air-conditioning and refrigeration, New Delhi, India, Sept 26-28. pp13-25.

2. Arora CP (2000) A text book on refrigeration and airconditioning, Ch 4 refrigerants, Tata Mcgraw Hill,New Delhi)

3. CARE products (2009) http://www.careproducts.

Research article

CIndian Society for Education and Environment (iSee)

J.Sci.Technol.
4. INFRAS (2000) National CFC consumptions phase out plan for India focusing on refrigeration service sector.

5. Kapil S (2008) The R12 and R22 phase out in India: Preparing for critical changes in the refrigerant landscape. Air-conditioning refrig. J. 11(4), 103-106.

6. Othmar S and Adrian S (1998) Technology transfer and policy barriers in commercial refrigeration and airconditioning. Proc. of IIR conf. on emerging trends in air-conditioning and refrigeration. New Delhi, India, 18-20 March, pp399-416.
"Eco-friendly refrigerant"

http://www.indjst.org
Alka \& Vipin Indian 